\title{
PARTICIPATION AND PERFORMANCES IN COMPETITIONS: LATVIAN ORIENTEERING DEVELOPMENT EVIDENCE
}

\author{
Baiba Smila \\ Andra Fernāte \\ Latvian Academy of Sport Education, Latvia
}

\begin{abstract}
Previous efforts to depict sport development opportunities resulted in a sport development metaphor, the participation pyramid (Sotiriadou, Shilbury, \& Quick, 2008). The base of the sport development metaphor represents the relationship between mass and elite participation (Shilbury, Sotiriadou, \& Green, 2008) and medals won during the Olympic Games (Sotiriadou \& De Bosscher, 2013). The most important international competitions may, therefore, best represent overall sport systems (Sparvero, Chalip, \& Green, 2008), but competition opportunities for athletes are the factor contributing to elite success.

The aim of this study is to determine the relationship between mass and elite orienteers' participation and elite orienteers' performances at the most important national and international orienteering competitions. Methods: the official most important orienteering national and international competition results from 2001 to 2016 were obtained from the websites of each annual organizing committee, linked to the International Orienteering Federation website and mathematical statistics was conducted.

The results confirmed a strong, medium and weak relationship between mass and elite orienteers' participation and elite orienteers' performances in the most important national and international orienteering competitions. Orienteers' movement up the participation pyramid is not automatic.
\end{abstract}

Keywords: participation in orienteering competition, performance in orienteering competition, orienteering development.

\section{Introduction}

There are different approaches to the evaluation of sport development. In such a sport development model as a pyramid, the main goal is to organize mass sport and recreational activities, as well as to endure the preparation of future champions. This study will analyse whether the orienteering development is linear and whether it is reflected as a participation pyramid, the basis of which is participation in mass sport and the apex is participation on an elite level, or whether its development is complex (Sotiriadou et al., 2008). 
What is the relation between elite and grassroot sport, is sport meant for medals of some elite athletes or for the improvement of human health? The development of elite sport is considered to be dependent on the participant participation in grassroot sport or independent of participant participation in grassroot sport, but in this case an early selection of potential top athletes is carried out, this approach is less supported (Houlihan \& Green, 2008).

Research shows that the budding top athletes need to adapt to intensive, sport-specific training programmes to be internationally competitive and to succeed; however, these programmes should be implemented only gradually and at the time appropriate for the development of the new athlete (Côté \& Vierimaa, 2014), if these conditions are not taken into consideration, it promotes the drop-outs of new athletes. In many countries, a structured system and a policy related to it is essential for sport development in the sport system. Many countries still specify the system, policy and ways that are necessary for a sustainable development of the sport system (Berger et al., 2008).

This article will explore the orienteering sport development in Latvia, taking into consideration the relationship between high performance sport and participation. The aim of this study is to determine the relationship between mass and elite orienteers' participation and elite orienteers' performances in the most important national and international orienteering competitions.

\section{Theoretical Framework}

This subchapter will discuss the understanding of the essence of sport development and its characteristic indicators, such as "participation" and "performance".

Sport development can be defined as a dynamic, systemic (inputthroughput-output) and spiral-type system, in which sport development is a dynamic process, in which the involvement of the parties interested in the sport development provides the necessary strategies and paths of sport development, which promote involvement of sports participants, retention/transition and support (Sotiriadou et al., 2008). Thus, sport development is systemic, its development depends on the set goal to promote mass involvement or to develop talented athletes, i.e. to develop through sport or to develop the sport (Sotiriadou et al., 2016). Sport has three main results - achievements, participation and personal development. Unfortunately, governments usually want to achieve one of them at the expense of another (Côté \& Vierimaa, 2014).

Research on participation in sport has established that it is affected by several variables characterizing the participation - cognitive, psycho-social and situational. They can be divided into: socio-individual characteristics (e.g., age, gender and ethnicity); psychological predispositions (e.g., attitudes or 
motivations); socio-cultural influences (e.g., household socio-economic status, family support and peer influence); situational or environmental factors (e.g., school size, urban/rural setting, environmental aesthetics and transportation) (Berger et al., 2008).

There is a lot of research done on gender differences in participation in sports that suggest that girls and women participate in sport less, compared to boys and men (Berger et al., 2008; Hébert-Losier et al., 2015).

Participation in sport is associated with several benefits for improving health, but there is very little evidence that improvements of health are a result of participation in sport. The improved health aspects from sport participation were also often associated with recreational play rather than with competition (Eime et al., 2013a; Eime et al., 2013b). It could be possible that sport tried to involve individuals, who were healthy and well-developed. Thus, they are teenagers, who already are physically competent and are happy to engage in sports (Vella et al., 2014). Teenagers in sport often create a self-selected sample.

Participation in sport increases in late childhood and early adolescence, i.e. at the age of 12 for girls, but at the age of 15 boys reaches the maximum in participation in sport. An excessive emphasis on the result promotes sport dropouts during adolescence (Telama et al., 2006; Telama, 2009).

Unfortunately, youth participation in sport is not always associated with their positive development (Zarrett et al., 2009). Both in the talent development models in sport and the positive youth development model, the longest existing and necessary element is support (Harwood \& Johnston, 2016), where, for example, staff supporting elite orienteers see themselves not as providers of a service, but as members of the team (Henriksen, 2015).

Without a deep understanding of grassroot sport in the sport development processes, in particular the understanding of youth and their participation in sport, it is impossible to create an evidence-based policy and the benefits provided by participation in sport cannot be achieved (Berger et al., 2008). Grassroot sporting events can attract individuals to sport development and increase their active participation through targeted training and participation in events (Skinner et al., 2008). If it is desired to involve in sport as many adult participants as possible, alternative involvement points should be created, for instance, from participant motivation, which eliminate the barriers caused by socio-ecological factors (Rowe et al., 2016).

The developmental model of sport participation reflects the three dimensions of participation in sport: participation in recreation through selection, elite achievements through selection and elite achievements through early specialization. Two of these dimensions - participation in recreation through selection, elite achievements through selection - have the same basis the age of 6-12 years. After this selection age group, the participants in sport can 
choose whether to get involved in sport as recreation - the recreational age after 13 years of age, or to focus more on the achievement sport - the specialization period from 13-15 years of age, serious involvement after 16. The final result of these two approaches are different achievements, but they have a similar benefit to the physical health and psycho-socially. The third approach - elite achievements through early specialization, promotes elite achievements, but because of it health may suffer and there may be a loss of happiness (Côté \& Fraser-Thomas, 2007). In turn, the age of peak performance for both male and female orienteers ranged from 27 to 31 years (Hébert-Losier et al., 2015).

Seven paths have been identified in sport development, which indicates a non-linear sport development, which allows participants to enter a sport, leave the sport or to repeatedly return to it at different participation levels. The nonlinear approach in sport developments shows that many people participate in sports without the wish to reach the highest level. However, others think that the given opportunities and talent promote the transition to the higher levels in championships and people want to become elite athletes that reach the highest achievements in their career. At the end of their careers, some athletes want to leave the sport. In turn, others return to sport at an elite level in another type of sport, while others, after leaving active participation in sport, become coaches, volunteers or work in the media, or leave the elite and participate in championships of a public level (Sotiriadou et al., 2016).

Competitive performance by itself is an inadequate criterion for talent identification because it can be affected by a number of other factors that are obscured when only performances at competitions are taken into account. However, it can be used as a criterion when transitioning from one level to another and it is used in determining talent (Brouwers et al., 2012). The most important international competitions may, therefore, best represent overall sport systems (Sparvero, Chalip, \& Green, 2008), but competition opportunities for athletes is the factor contributing to elite success, because the role of competitions increases during specialization, they help to improve skills and provide international experience (Brouwers et al., 2012). We were interested in the opportunity to explore Latvian orienteering development pathway, by determining the relationship between grassroots and elite orienteer's participation and elite orienteer's performances at the most important national and international orienteering competitions.

\section{Methodology of the Research}

In order to determine the relationship between grassroots and elite orienteers' participation and elite orienteers' performances in the most important national and international orienteering competitions, the official most important 
orienteering national competition (Latvian Cup (LC) - Latvijas kauss) participation and international competition (European Youth Orienteering Championship (EYOC)) results from 2001 to 2016 were analysed, which were obtained from the websites of each annual organizing committee, obtained from the websites of each annual organizing committee, most of them linked to the International Orienteering Federation website, were analysed in the period of 2001 to 2016 (youth groups WM12; WM14; WM16; WM18; WM20).

The Latvian Cup (LC) is an orienteering championship series (18-25 championships), in which the best athletes of the year are determined in each Latvian Cup group from WM 12- WM 80. In the LC overall score, the 7-8 best results are summed up. When analysing LC results, those youth participants were selected, who have participated and received a full LC overall score. SPSS Statistics (version 22.0) data processing programme was used for data analysis, where descriptive statistics was carried out. Kolmogorov-Smirnov criterion was used to determine whether the data are parametric or non-parametric. Nonparametric statistics correlation analysis method was used to determine Spearman`s correlation coefficient.

\section{Results}

From 2001 till 2016, 5649 young adults have participated in the Latvian Cup (LC) championship series, from which 2168 are female (W=38.3\%) and 3481 - male $(\mathrm{M}=61.7 \%)$. The average number of participants in each age group

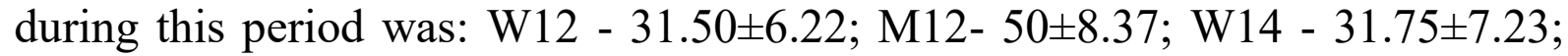
M14 - 52.56 \pm 10.32 ; W16 - 31.31 \pm 5.82 ; M16- 50.38 \pm 11.89 ; W18 - 25.50 \pm 7.16 ; M18- 40 \pm 10.19 ; W20 - 15.89 \pm 4.45 ; M20 - 24.44 \pm 7.24 . The total number of participants during this time period in each age group is shown in Figure 1, which also shows that women participate less in the Latvian Cup championships than men in all age groups and the largest number of participants in both the women and the male group is at the age of 14 .

Figure 1 illustrates the ratio of the total number of participants in each age group and the selected participants (S) with an overall score in each age group by genders during the researched time period. 956 women, which is $44 \%$ percent of the overall number of participants, and 1507 men (43.3\%) have obtained an overall score in these championships. 
Baiba Smila, Andra Fernāte. Participation and Performances in Competitions: Latvian Orienteering Development Evidence

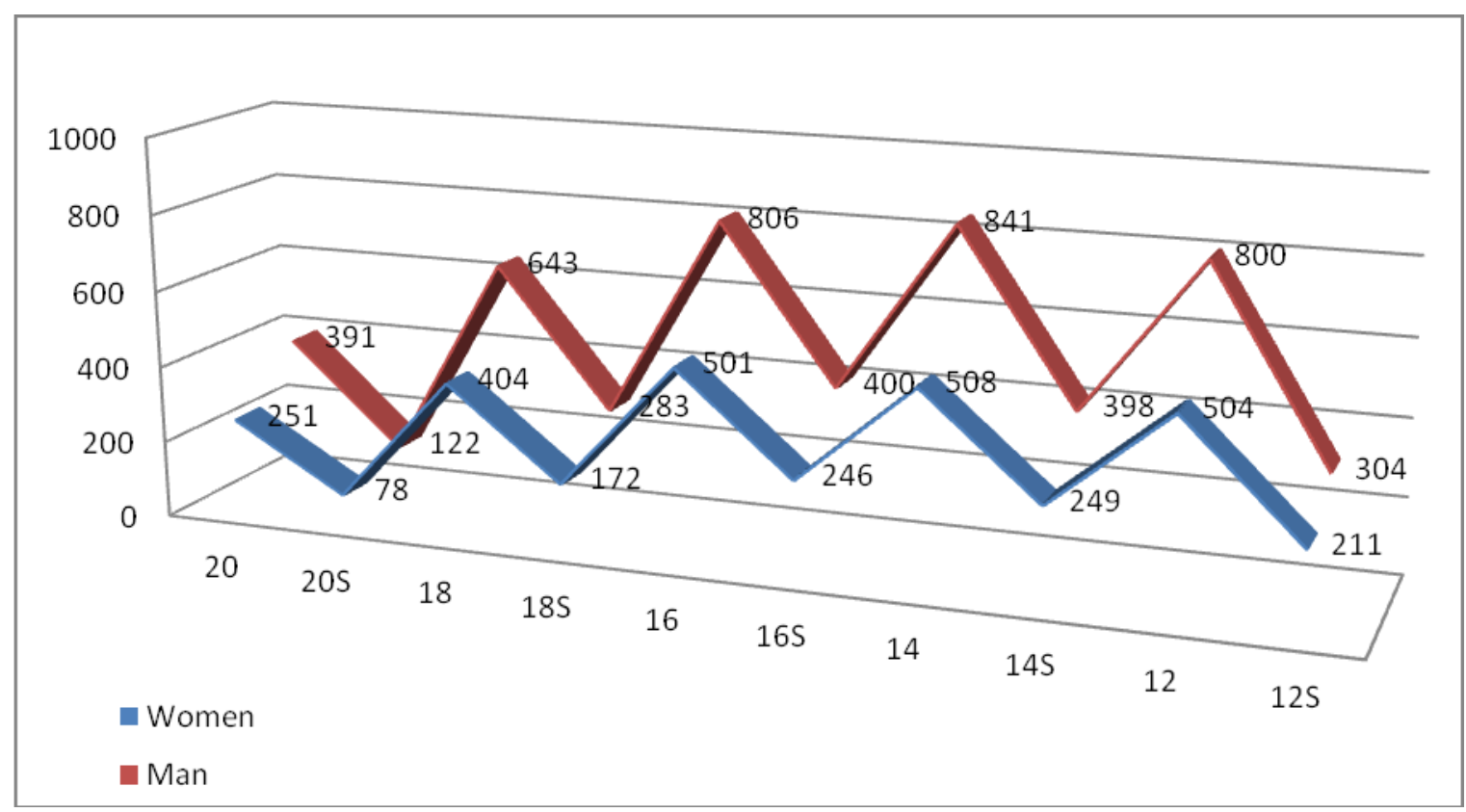

Figure 1 The total number of participants and the selected participants (S) with a overall score in each age group in the Latvian Cup championships from 2001 to 2016

In each age group in the Latvian Cup championships from 2001 to 2016 the relation between the number of selected (S) participants with a overall score and the total number of participants ranges between $1 / 3.2-1 / 2.03$, where the groups have the following proportion: W12 - $41.8 \%$; M12- $38 \%$; W14 - $49 \%$; M14 $47.3 \%$; W16 - 49.1 \%; M16- 49.6 \%; W18 - $42.5 \%$; M18- $44 \%$; W20 - $31 \%$; M20- $31.2 \%$.

There is a strong and a moderate correlation between the number of selected participants (S) with a overall score and the number of all participants in the W20 group $\left(\mathrm{r}_{\mathrm{s}}=.679, \mathrm{p}<0.01\right)$; W18 $\left(\mathrm{r}_{\mathrm{s}}=.699, \mathrm{p}<0.01\right)$; W16 $\left(\mathrm{r}_{\mathrm{s}}=.625\right.$, $\mathrm{p}<0.01)$; W14 $\left(\mathrm{r}_{\mathrm{s}}=.522, \mathrm{p}<0.05\right)$; W12 $\left(\mathrm{r}_{\mathrm{s}}=.563, \mathrm{p}<0.05\right)$, as well as a moderate correlation between the number of all participants in the W12 group and the $\mathrm{W} 14$ group $\left(\mathrm{r}_{\mathrm{s}}=.529, \mathrm{p}<0.05\right)$, but a weak correlation between the number of selected participants with a overall score in the $\mathrm{W} 12$ and $\mathrm{W} 14$ groups $\left(\mathrm{r}_{\mathrm{s}}=.452\right.$, $\mathrm{p}<0.05$ ).

The greater the number of participants in the W12S, W16S, W16 groups (LC), the better the results in EYOC W16 individual distance $\left(\mathrm{r}_{\mathrm{s}}=-.603\right.$, $\left.\mathrm{p}<0.01 ; \mathrm{r}_{\mathrm{s}}=-.466, \mathrm{p}<0.05 ; \mathrm{r}_{\mathrm{s}}=-.582, \mathrm{p}<0.01 ;\right)$, while the greater the number of participants in the W12 and W16S groups (LC), the better the results in the EYOC W16 sprint distance $\left(\mathrm{r}_{\mathrm{s}}=-.519, \mathrm{p}<0.05 ; \mathrm{r}_{\mathrm{s}}=-.519, \mathrm{p}<0.05\right)$ (Figure 2). There is a moderate positive correlation between the success in the EYOC W16 sprint distance and in the EYOC W16 individual distance $\left(\mathrm{r}_{\mathrm{s}}=.522, \mathrm{p}<0.05\right)$. 


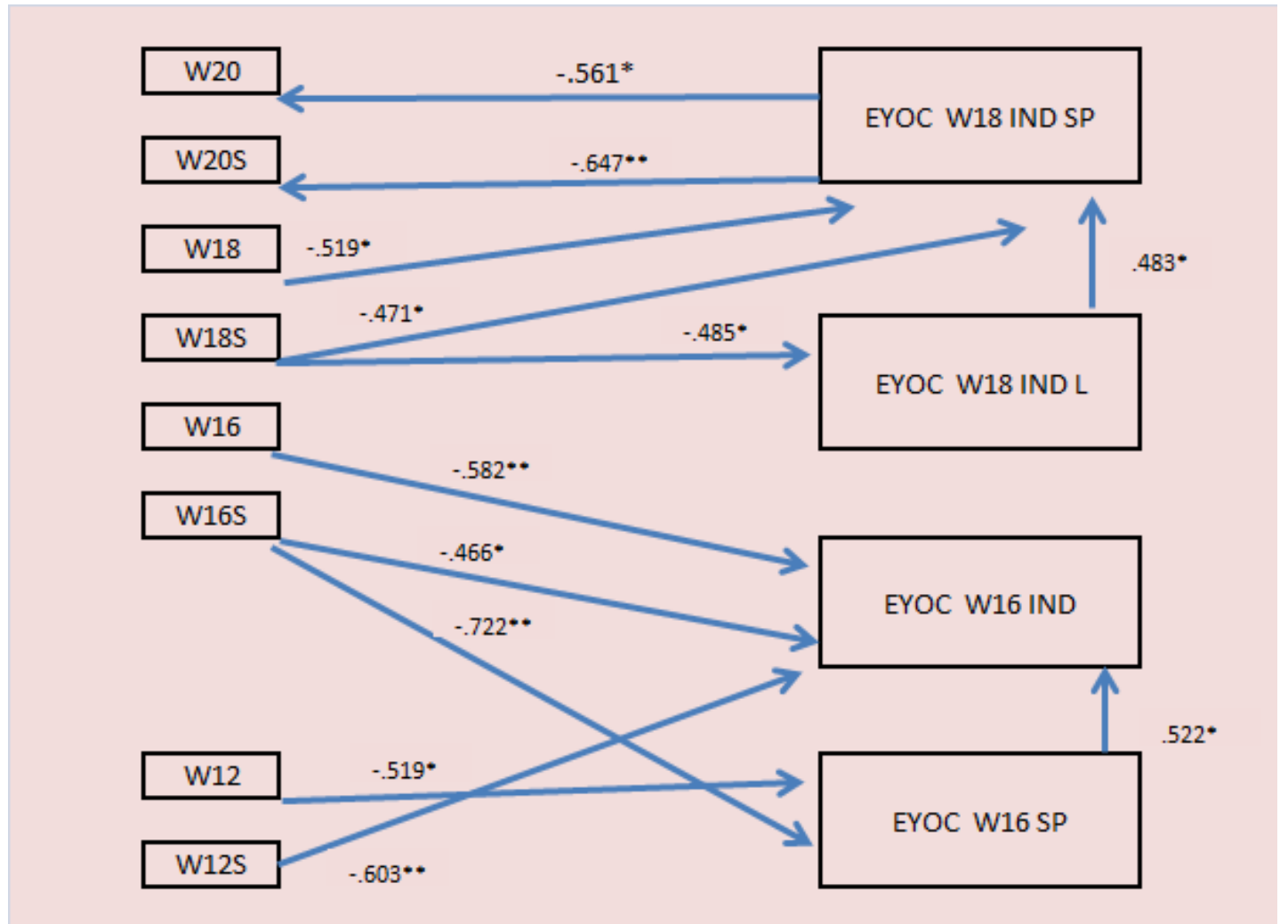

Figure 2 Correlations between the total number of participants, the selected participants

(S) with a overall score in each age group in the Latvian Cup championships and the best performance in the EYOC individual and sprint distance (2001-2016)

The larger the number of participants in the W18S group (LC), the better the results in the EYOC W18 individual long distance $\left(\mathrm{r}_{\mathrm{s}}=-.485, \mathrm{p}<0.05\right)$ and the sprint distance $\left(r_{s}=-.471, p<0.05\right)$, while the larger the number of participants in the W18 group (LC), the better the results in the EYOC W18 sprint distance $\left(r_{s}=-.519, p<0.05\right)$ (Figure 2), which, in turn, determines the number of participants in the W20S and W20 $\left(\mathrm{r}_{\mathrm{s}}=-.647, \mathrm{p}<0.01 ; \mathrm{r}_{\mathrm{s}}=-.561\right.$, $\mathrm{p}<0.05)$. There is a weak correlation between the success in the EYOC W18 individual distance and the EYOC W18 sprint distance and $\left(\mathrm{r}_{\mathrm{s}}=.483, \mathrm{p}<0.05\right)$.

There is a strong, medium strong and weak correlation between the number of selected participants (S) with an overall score and the number of all participants M18 ( $\left.\mathrm{r}_{\mathrm{s}}=.958, \mathrm{p}<0.01\right)$; M16 $\left(\mathrm{r}_{\mathrm{s}}=.763, \mathrm{p}<0.01\right)$; M14 $\left(\mathrm{r}_{\mathrm{s}}=.537\right.$, $\mathrm{p}<0.05)$; M12 ( $\left.\mathrm{r}_{\mathrm{s}}=.477, \mathrm{p}<0.05\right)$, as well as a moderate correlation between the total number of participants in the M16 group and M18 group ( $\mathrm{r}_{\mathrm{s}}=.615, \mathrm{p}<0.01$ ) and the number of selected participants $(\mathrm{S})$ with an overall score $\left(\mathrm{r}_{\mathrm{s}}=.548\right.$, $\mathrm{p}<0.05$ ), but there is a strong correlation between the number of selected participants with an overall score in M16 and the total number of participants in the M18 group $\left(\mathrm{r}_{\mathrm{s}}=.673, \mathrm{p}<0.01\right)$, and also the number of selected participants with an overall score in the M18 group $\left(\mathrm{r}_{\mathrm{s}}=.651, \mathrm{p}<0.01\right)$. 
There is a moderate positive correlation between the total number of participants in the M14 group and the M18 group ( $\left.\mathrm{r}_{\mathrm{s}}=.527, \mathrm{p}<0.01\right)$ and the number of selected participants (S) with an overall score $\left(r_{s}=.614, p<0.01\right)$, but a moderate positive and strong correlation between the total number of participants in the M14 group and the M16 group ( $\left.\mathrm{r}_{\mathrm{s}}=.579, \mathrm{p}<0.01\right)$ and the number of selected participants $(\mathrm{S})$ with an overall score $\left(\mathrm{r}_{\mathrm{s}}=.781, \mathrm{p}<0.01\right)$.

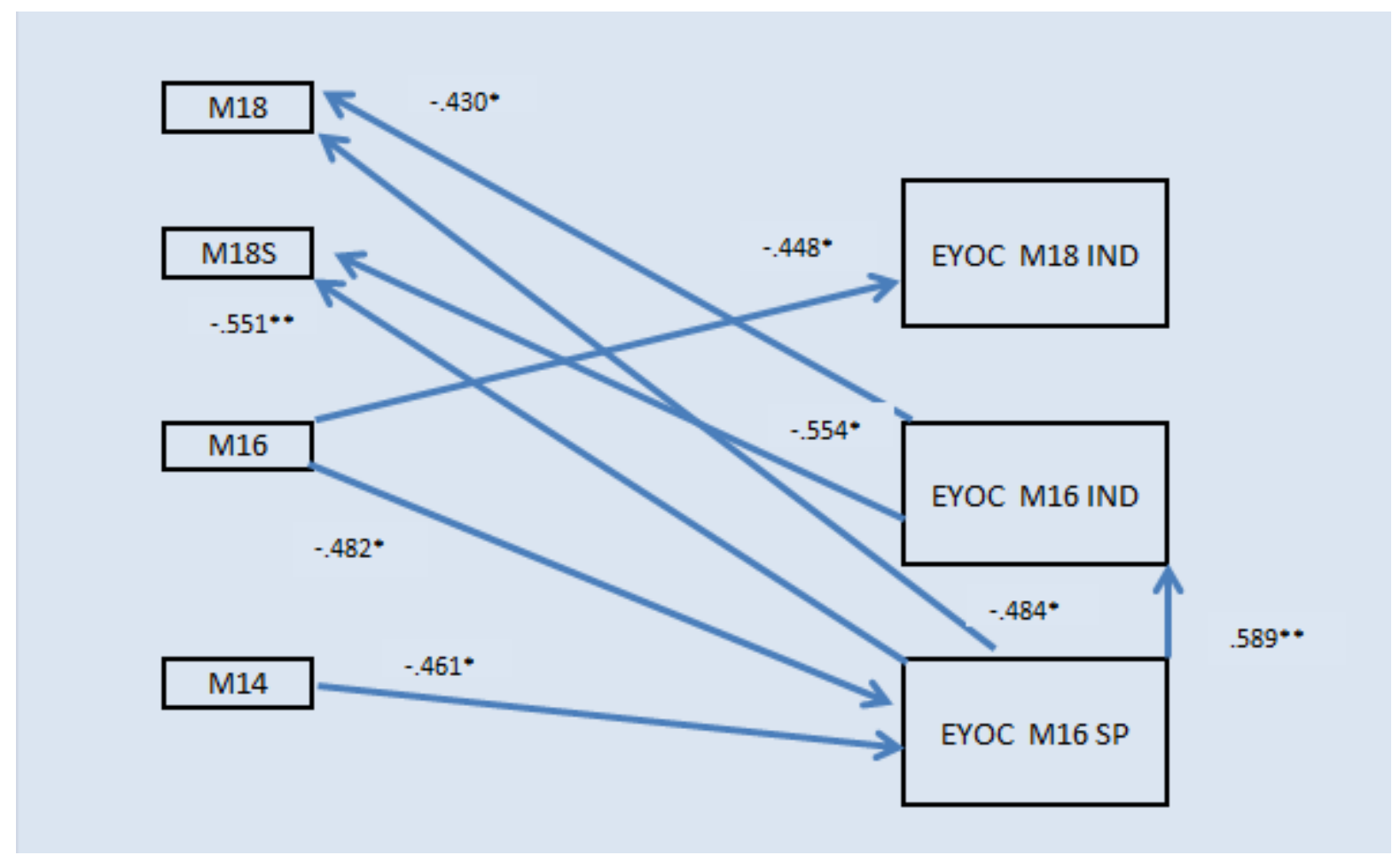

Figure 3 Correlation between the total number of participants, the selected participants (S) with an overall score in each age group in the Latvian Cup championships and the best performance in the EYOC individual and sprint distance (2001-2016)

There is a weak negative correlation between the number of selected participants with an overall score in the M14 group and the number of selected participants with an overall score in the M20 group ( $\left.\mathrm{r}_{\mathrm{s}}=-.468, \mathrm{p}<0.05\right)$, and also a moderate positive correlation between the number of selected participants with an overall score in the M16 group $\left(\mathrm{r}_{\mathrm{s}}=.547, \mathrm{p}<0.05\right)$. There is a weak correlation between the number of selected participants with an overall score in M12 and the number of selected participants with an overall score in the M14 group $\left(\mathrm{r}_{\mathrm{s}}=.454, \mathrm{p}<0.05\right)$.

However, the best results of individual championships in EYOC M18 has a weak negative correlation with the total number of participants in the M16 group $\left(\mathrm{r}_{\mathrm{s}}=-.448, \mathrm{p}<0.05\right)$, but the best result obtained in the EYOC M16 sprint has a weak negative correlation with the total number of participants in the M16 group 
$\left(\mathrm{r}_{\mathrm{s}}=-.482, \mathrm{p}<0.05\right)$, the total number of participants in the M14 group $\left(\mathrm{r}_{\mathrm{s}}=-.461\right.$, $\mathrm{p}<0.05$ ), as well as a weak and moderate negative correlation with the total number of participants in the M18 group $\left(\mathrm{r}_{\mathrm{s}}=-.484, \mathrm{p}<0.05\right)$ and the number of selected participants with an overall score $\left(\mathrm{r}_{\mathrm{s}}=-.551, \mathrm{p}<0.05\right)$ (Figure 3$)$. There is a weak and moderate negative correlation between the individually best result shown in the EYOC M16 and the total number of participants in the M18 group $\left(r_{s}=-.430, p<0.05\right)$ and the number of selected participants with an overall score $\left(\mathrm{r}_{\mathrm{s}}=-.554, \mathrm{p}<0.05\right)$. There is a moderate positive correlation between the achievements in the EYOC M16 individual distance and in the EYOC M16 sprint distance and $\left(\mathrm{r}_{\mathrm{s}}=.589, \mathrm{p}<0.01\right)$.

\section{Discussion}

Taking into consideration the total number of participants in each age group in the Latvian Cup championships from 2001 to 2016, it can be concluded that the orienteering development in Latvia is complex (after Sotiriadou et al., 2008), because there is a smaller number of participants in the age group WM12 than in WM14 and it only slightly decreases in the MW16 groups, which is why the orienteering development is not reflected as a participation pyramid, at the basis of which is participation in mass sport and in the apex - participation on an elite level. Participation in sport increases in late childhood and early adolescence, i.e. at 12 for girls, but boys reach the maximum in participation in sport at 15 (Telama et al., 2006; Telama, 2009), while in orienteering girls and boys reach the maximum in participation in LC competitions in the WM14 groups.

A non-linear orienteering development (Sotiriadou et al., 2016) is also shown by the fact that many people participate in the Latvian Cup championships without the desire to reach the highest level, because only 43$44 \%$ of the young participants have participated and received an overall score. According to the developmental model of sport participation (Côté \& FraserThomas, 2007), which reflects the three dimensions of participation in sport: participation in recreation through selection, elite achievements through selection and elite achievements through early specialization. Orienteering is characterized more by elite achievements through selection, specialization period from 13-15, but serious involvement after 16 .

\section{Conclusions}

The study results show that in all age groups both genders have a strong and moderate correlation between the number of selected participants (S) with an overall score (LC) and the total number of participants, as well as the success 
obtained in the EYOC WM16 individual and the WM16 sprint distance and between the number of selected participants (S) with an overall score (LC) and the total number of participants and also in the EYOC WM18 individual distance and between the number of selected participants (S) with an overall score (LC) and the total number of participants.

\section{References}

Berger, I. E., O’Reilly, N., Parent, M. M., Séguin, B., \& Hernandez, T. (2008). Determinants of Sport Participation Among Canadian Adolescents. Sport Management Review, 11, 3, 277-307, http://dx.doi.org/10.1016/S1441-3523(08)70113-X.

Brouwers, J., De Bosscher, V., \& Sotiriadou, P., (2012). An examination of the importance of performances in youth and junior competition as an indicator of later success in tennis. Sport Management Review, 15, 4, 461-475, http://dx.doi.org/10.1016/j.smr. 2012.05.002.

Côté, J., \& Fraser-Thomas, J. (2007). Youth involvement in Sport. In: Crocker, P. (Ed.), Introduction to Sport Psychology: A Canadian Perspective. Toronto: Pearson Prentice Hall.

Côté, J., \& Vierimaa, M. (2014). The developmental model of sport participation: 15 years after its first conceptualization. Science \& Sports, 29, 0, 63-69, http://dx.doi.org/ 10.1016/j.scispo.2014.08.133

Eime, R. M., Young, J. A., Harvey, J. T., Charity, M. J., \& Payne, W. R. (2013a). A systematic review of the psychological and social benefits of participation in sport for adults: informing development of a conceptual model of health through sport. International Journal of Behavioral Nutrition and Physical Activity, 10: 135. doi:10.1186/1479-5868-10-135

Eime, R. M., Young, J. A., Harvey, J. T., Charity, M. J., \& Payne, W. R. (2013b). A systematic review of the psychological and social benefits of participation in sport for children and adolescents: informing development of a conceptual model of health through sport. International Journal of Behavioral Nutrition and Physical Activity, 10: 98. doi:10.1186/1479-5868-10-98

Harwood, Ch., \& Johnston, J. (2016). Positive Youth Development and Talent Development is there a Best of the Both Worlds. In: Holt, N. L. (Ed.). Positive Youth Development Through Sport: Second Edition. (pp. 113-125). Routledge

Hébert-Losier, K., Platt, S., \& Hopkins, W. G. (2015). Sources of Variability in Performance Times at the World Orienteering Championships. Med Sci Sports Exerc., 47 (7):152330. doi: 10.1249/MSS.0000000000000558.

Henriksen, K. (2015). Developing a High-Performance Culture: A Sport Psychology Intervention From an Ecological Perspective in Elite Orienteering. Journal of Sport Psychology in Action, 6: 3, 141-153, DOI: 10.1080/21520704.2015.1084961

Houlihan, B., \& Green, M. (2008). Comparative elite sport development. In: Houlihan, B. \& Green, M. (Eds.), Comparative elite sport development: systems, structures and public policy (pp. 1-21). London: Elsevier

Rowe, K., Shilbury, D., Ferkins, L., \& Hinckson, E. (2016). Challenges for sport development: Women's entry level cycling participation, Sport Management Review, 19, 4, 417-430, http://dx.doi.org/10.1016/j.smr.2015.11.001. 
Shilbury, D., Sotiriadou, K. P., \& Green, B. Ch. (2008). Sport Development. Systems, Policies and Pathways: An Introduction to the Special Issue, Sport Management Review, Volume 11, Issue 3, Pages 217-223, ISSN 1441-3523, http://dx.doi.org/10.1016/S14413523(08)70110-4.

Skinner, J., Zakus, D. H., \& Cowell, J. (2008). Development through Sport: Building Social Capital in Disadvantaged Communities. Sport Management Review, 11, 253-275.

Sotiriadou, K., \& De Bosscher, V. (2013). Managing High Performance Sport. Routledge.

Sotiriadou, K., Shilbury, D., \& Quick, Sh. (2008). The attraction, retention/transition, and nurturing process of sport development: Some Australian evidence. Journal of sport management, 22 (3), 247-272. http://epublications.bond.edu.au/hsm_pubs/190

Sotiriadou, P., Brouwers, J., \& De Bosscher, V. (2016). High performance development pathways. In: Sherry, E., Schulenkorf, N., \& Phillips, P. (Eds.). Managing Sport Development: An International Approach. (pp. 63-76), Routledge.

Sparvero, E., Chalip, L., \& Green, C. (2008). United States. In: Houlihan, B. \& Green, M. (Eds.), Comparative elite sport development: systems, structures and public policy (pp. 243-293). London: Elsevier.

Telama, R., Yang, X., Hirvensal, M., \& Raitakari, O. (2006). Participation in Organized Youth Sport as a Predictor of Adult Physical Activity: A 21-Year Longitudinal Study. Pediatric Exercise Science. 18: 1, 76-88.

Telama, R. (2009). Tracking of Physical Activity from Childhood to Adulthood: A Review. The European Journal of Obesity, 2: 187-195.

Vella, S. A., Cliff, D. P., \& Okely, A. D. (2014). Socio-ecological predictors of participation and dropout in organised sports during childhood. International Journal of Behavioral Nutrition and Physical Activity. 11: 62. doi: 10.1186/1479-5868-11-62.

Zarrett, N., Fay, K., Li, Y., Carrano, J., Phelps, E., \& Lerner, R. M. (2009). More than child's play: Variable- and pattern-centered approaches for examining effects of sports participation on youth development. Developmental Psychology, 45, 368-382. 